\title{
Photoselective Nets Alter Apple Canopy Air Temperature and Carbon Translocation during Dormancy and Budbreak
}

\author{
Alexandra Boini and Enrico Muzzi \\ Department of Agricultural and Food Sciences (DISTAL), Alma Mater \\ Studiorum - University of Bologna, Viale G. Fanin 46, 40127 Bologna, Italy
}

Aude Tixier

UMR 1347 Agroécologie, AgroSup/INRA/uB, 21000 Dijon, France

Maciej Zwieniecki

Department of Plant Sciences, University of California, Davis, CA

Luigi Manfrini and Luca Corelli Grappadelli

Department of Agricultural and Food Sciences (DISTAL), Alma Mater Studiorum - University of Bologna, Viale G. Fanin 46, 40127 Bologna, Italy

Additional index words. apple, budbreak, dormancy, fruit tree crop, light, photoselective nets, soluble sugars, spectrum, starch

\begin{abstract}
Photoselective nets were used to examine apple shoot physiology during dormancy and budbreak. Two trials were conducted: one in the field and one in controlled conditions. In the first, three colored nets (red, blue, and white, shading $20 \%$ ) covered sections of single trees, leaving an empty portion as control, from December to April. The white net increased canopy air temperature compared with the blue one. Differences were found in carbohydrate seasonal patterns; however, it appeared that soil temperature had higher impacts on sugar movement in the trees. No differences were found in bud phenology. In the second trial, cuttings were placed in boxes constructed with the same-colored nets and monitored from the end of February to April. Results showed differences in phenology and carbohydrate translocation. The white box hastened bloom and its cuttings had higher amounts of carbohydrates at the end of the trial. On the contrary, the blue box delayed bloom while resources were still being consumed and its cuttings had the lowest amounts of reserves at the end of the trial. These results add new insights on apple physiology under different light spectra and commercial applications should not be excluded for improving crop management.
\end{abstract}

Winter survival of temperate fruit tree crops is the phase of inhibited growth known as dormancy (Faust et al., 1997), controlled by mechanisms occurring in the possibly affected parts of the tree (Campoy et al.,

Received for publication 20 Nov. 2020. Accepted for publication 20 Jan. 2021.

Published online 21 September 2021.

The work presented here was carried out at the Department of Plant Sciences, UC Davis, One Shields Avenue, Davis, CA.

The trials were partially supported by the Carbohydrate Observatory project. We are grateful to Astrid Volder and Matthew Edmund Gilbert for helping to set up the experiment in the field; Filipa Grilo, Juan J. Polari, and Adele Amico Roxas for precious technical support in data collection; and Riccardo Lo Bianco for helpful advice when revising the manuscript.

A.B. is the corresponding author. E-mail: alexandra. boini@unibo.it.

This is an open access article distributed under the CC BY-NC-ND license (https://creativecommons. org/licenses/by-nc-nd/4.0/).
2011). To date, the classification scheme proposed by Lang et al. (1987) is the most used, adopting the terms "paradormancy" (or apical dominance, occurring during the vegetative period), "endodormancy" (deep dormancy, occurring during winter), and "ecodormancy" (occurring during late winter and spring).

To overcome winter, woody plant species depend on adequate reserves (Loescher et al., 1990). Following the onset of dormancy, low temperatures and lack of photosynthesis lead to starch conversion into soluble carbohydrates, whose concentration in plant organs reaches its highest peak in full winter, conferring cold and frost resistance (Hillmann et al., 2016; Yoshioka et al., 1988). Soluble carbohydrates will provide energy for maintenance respiration in winter, and growth resumption and development of new organs, such as flowers and leaves, in spring. Hence, before and during breaking of dormancy, conversion of nonsoluble to soluble sugars takes place (Charrier et al., 2013; Hartmann and Trumbore, 2016; Tixier et al., 2019) in the shoots and is followed by translocation to the buds (Bonhomme et al., 2010; Lacointe et al., 2004). In fact, trees respond to root-tocanopy temperature gradients by changing their local nonsoluble carbohydrate management and within-tree redistribution (Sperling et al., 2017; Zwieniecki et al., 2015), which is important during periods of low transpiration and for periods of intense biological activity [e.g., budbreak in spring (Gordon and Dejong, 2007)]. Dormancy release initiates when the soil is colder than the canopy, implying allocation of nonsoluble carbohydrates from the roots to the warmer canopy (Sperling et al., 2017; Zwieniecki et al., 2015). Nevertheless, the described allocations would not occur if chilling is not fulfilled (Marafon et al., 2011).

Several deciduous woody species bloom before vegetative development, such as stone fruits and nuts. Therefore, the early stages of reproductive growth depend almost completely on stored carbohydrates (Westwood, 1978). Other species are not totally dependent on reserves. Apple spur leaves are almost fully expanded before bloom; however, the early development of apple flower clusters after budbreak will initially use stored reserves of carbohydrates and nutrients (Hansen, 1971; Hansen and Grauslund, 1973). During dormancy, in nonphotoperiodic species, such as apple, pear, and other Rosaceae (Garner and Allard, 1923; Wareing, 1956), dormancy break is triggered in reverse order. Of course, species differ in the level and duration of chilling required for effective dormancy release (Coville, 1920; Couvillon and Erez, 1985). Thus, temperature is considered the most important external factor acting on dormancy signaling (Considine and Considine, 2016; Wang and Faust, 1988).

Light plays a part in regulating temperature and the hormonal components, occurring during the end of dormancy. Light induces transcriptional changes in grapevine quiescent buds, suggesting its importance during bud burst, sugar signaling for growth resumption, and chloroplast biogenesis (Signorelli et al., 2018). The timing of light application can have both promotive and inhibitive effects (Gur, 1985; Samish et al., 1967). Light quantity manipulation during dormancy and ecodormancy (Lang et al., 1987) showed promotive effects for peach (Buchanan et al., 1977; Freeman and Martin, 1981) and apricot (Campoy et al., 2010; Ruiz et al., 2005). An increase in light intensity

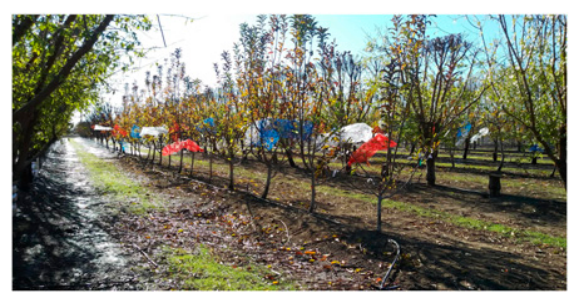

Fig. 1. Field experimental set-up. 
Table 1. Average air and stem temperature values of light treatments in the field.

\begin{tabular}{lcclcrr} 
Light treatments & Avg air temp $\left({ }^{\circ} \mathrm{C}\right)$ & SE & & Avg stem temp $\left({ }^{\circ} \mathrm{C}\right)$ & SE \\
\hline Control & 9.29 & \pm 0.0698 & ab & 9.18 & \pm 0.0535 & $\mathrm{a}$ \\
Red & 9.41 & \pm 0.0727 & $\mathrm{ab}$ & 9.36 & \pm 0.0543 & $\mathrm{a}$ \\
Blue & 9.07 & \pm 0.0707 & $\mathrm{a}$ & 9.20 & \pm 0.0538 & $\mathrm{a}$ \\
White & 9.55 & \pm 0.0731 & $\mathrm{~b}$ & 9.13 & \pm 0.0533 & $\mathrm{a}$ \\
\hline
\end{tabular}

Different letters, within columns, represent significant difference at $P<0.05$, using Student's $t$ test.

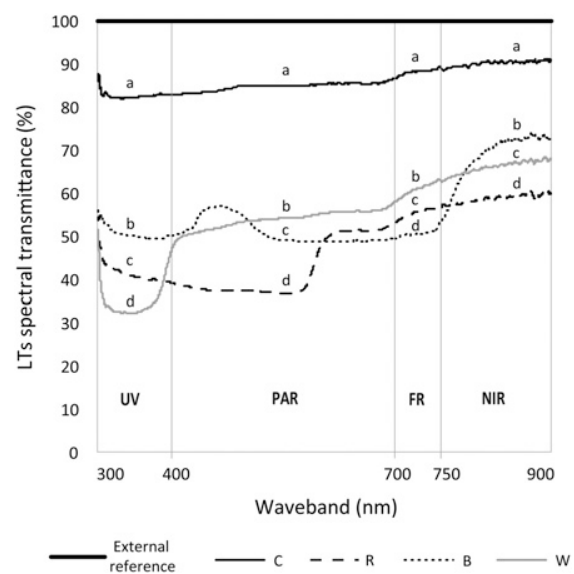

Fig. 2. Patterns of light treatment (LT) spectral transmittance in the field, ranging from 300 to $900 \mathrm{~nm}$. Different letters represent significant difference at $P<0.05$.

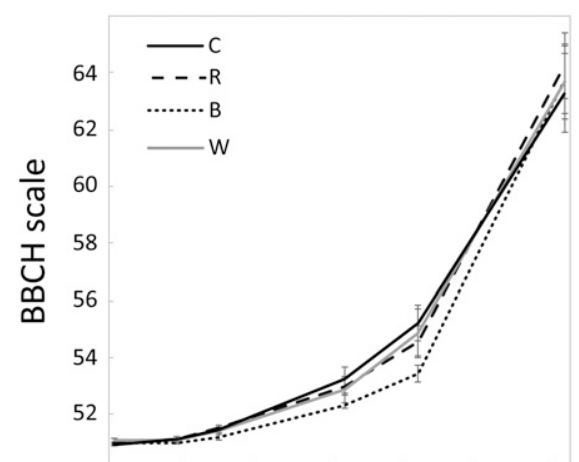

06/03 13/03 20/03 27/03 03/04 10/04 17/04 Time

Fig. 3. Flower bud phenology evolution of light treatments in the field, from the beginning of March to the second half of April. The absence of letters indicates no significance.

accelerated burst of postdormant perennial buds in spring (Rageau et al., 1998). However, studies focusing on postblossom growing season found inhibitory effects in apple, apricot, and grapevine (Jackson, 1969; Jackson and Palmer, 1977; Kohlet et al., 1996; Solomakhin and Blanke, 2008) and negative impacts of artificial shading on flower bud weight were found in Japanese pear during flower bud formation (Ito et al., 2003). There appears to be no information about the effect of light spectrum during dormancy in orchard systems, whereas different qualities of light have been widely investigated during dormancy in annual spe- cies, predominantly Arabidopsis thaliana. Light spectrum in orchards can be modified with the use of photoselective nets (Ganelevin, 2008), which alter the transmission of certain wavebands, compared with others. Thus, the ratios between various wavebands change. No research on light quality manipulation has taken place during dormancy in orchards; supposedly, due to the low economic interest in installing antimention the possible damage that winter snow can produce to operating netting systems and the trees below. However, research highlights positive effects of decreased incidence of solar radiation during dormancy and ecodormancy (Ruiz et al., 2005) on orchard productivity in Mediterranean climates, where there is a potential lack of chilling units, especially in a context of climate change. Consequent lower temperatures would decrease specific hormonal activity, in this case, gibberellins (Beppu et al., 2001), which are known to have negative impacts on flower bud development (Painter and Stembridge, 1972). Therefore, indirect shading originating from antihail nets may have positive effects when exiting ecodormancy, in a relatively warm Mediterranean climate, although the previously mentioned studies have been focusing on stone fruit.

This article aimed at studying light spectra manipulation effects on apple dormancy breaking and carbohydrate management. The results may give new insights of apple physiology and carbohydrate translocation while tential applications of photoselective nets during these periods, for improving management practices.

As light quality has proven to modify the microenvironment in terms of temperature (Arthurs et al., 2013), there may be effects on those phenological stages that occur during ecodormancy and budbreak.

\section{Materials and Methods}

Two trials were conducted: one in the orchard (field conditions) and one in the laboratory (controlled conditions).

Field, treatments, and weather. The trial took place in an experimental orchard at the University of California, Davis, where apple rows (cv. Gibson Golden Delicious) were alternated with almond rows. Each apple row was planted in consecutive years and consisted of 15 trees, spaced at $1.8 \mathrm{~m}$ along the hail systems in the winter period, not to exiting dormancy and budbreak, and of po-

\section{Field trial}

row and $4.5 \mathrm{~m}$ between rows. The apple cultivar, as a selection of Golden Delicious, requires $\approx 1200$ chilling units $(\mathrm{CU})$ to break dormancy (Hauagge and Cummins, 1991; Shaltout and Unrath, 1983). On 20 Dec. 2017, trees were selected from two apple rows planted in 2011 and 2012. Eight trees were chosen in the first and seven in the second one. The trees were trained as open vase, with four scaffold branches each, facing the four cardinal points. Three sectors were covered with three photoselective nets, where care was taken to avoid stray light, and one was left exposed, serving as the control (C). The photoselective nets shaded $20 \%$ and were red (R), blue (B), and white (W) (ChromatiNet Polysack Plastic Industries, D.N. Negev, Israel). The manufacturer indicated the $\mathrm{W}$ possessed an ultraviolet absorber. The experiment was set up as a randomized complete block of four light treatments (LTs) replicated on all the trees, which served as blocks (Fig. 1).

Weather data for the trial site (lat. $38^{\circ} 32^{\prime} 8$ $\mathrm{N}$, long. $121^{\circ} 46^{\prime} 35 \mathrm{~W}$ ) and environmental soil temperature were monitored from the Cimis (California Irrigation Management Information System) database, starting from the beginning of Nov. 2017, until the second half of Apr. 2018. CUs were obtained following the Utah model (Richardson et al., 1974) and degree days (DD) were calculated, with $10^{\circ} \mathrm{C}$ as the threshold temperature.

Spectral properties analysis. On 19 Jan. 2018 the net light spectra were assessed by a spectrometer (JAZ-EL200-XR1; Ocean Optics, Largo, FL), covering the band from ultraviolet to near infrared (NIR) (300-900 $\mathrm{nm})$. The quantification was carried out on four trees, where all four LTs were facing all four cardinal points. For each LT, three measurements were automatically generated. Reference measurements were also taken outside the orchard, in full light. Irradiance values $\left(\mathrm{W} \cdot \mathrm{m}^{-2}\right)$ were converted to $\mu \mathrm{mol} \cdot \mathrm{m}^{-2} \cdot \mathrm{s}^{-1}$ photosynthetically active radiation $(P A R)$; transmittance could then be obtained as the ratio between the external light input and the light intensity for each treatment and expressed as percentage.

Air and stem temperature. On 19 Jan. 2018 thermocouples were installed on three adjacent trees, in each LT. A needle was used to pierce a hole through the bark, until reaching the xylem, and thermocouples were then glued in place. Each LTs had three thermocouples: 1) monitoring air temperature, 2) monitoring stem temperature on the north side of one shoot, and 3) on the south side of the same shoot. The sensors were connected to a CR1000 datalogger (Campbell Scientific Inc., Logan, UT) and values were collected every $15 \mathrm{~min}$, until the middle of April. Before placing the system in the field, all thermocouples were calibrated.

Phenology. From the beginning of March to the second half of April, bud phenology was monitored, following the $\mathrm{BBCH}$ scale (Meier et al., 1994). For each LT, the initial number of monitored buds was 30. Full bloom was observed on 15 Apr. 2018. 


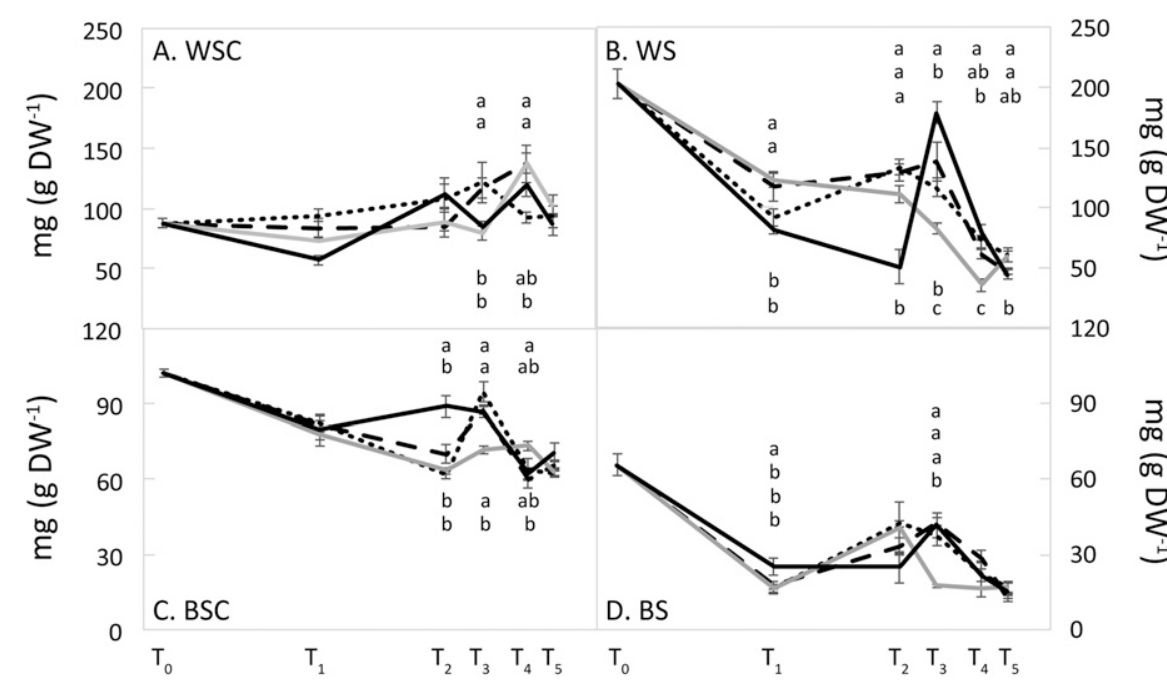

Sampling times

$-C--R \quad \cdots \cdot B-W$

Fig. 4. Dynamics of wood (A) soluble carbohydrates and (B) starch, and bark (C) soluble carbohydrates and (D) starch, during sampling times for each light treatment, in the field. T1 stands for 31 Jan.; T2 for 6 Mar.; T3 for 16 Mar.; T4 for 28 Mar.; and T5 for 4 Apr. 2018. Different letters represent significant difference at $P<0.05$.
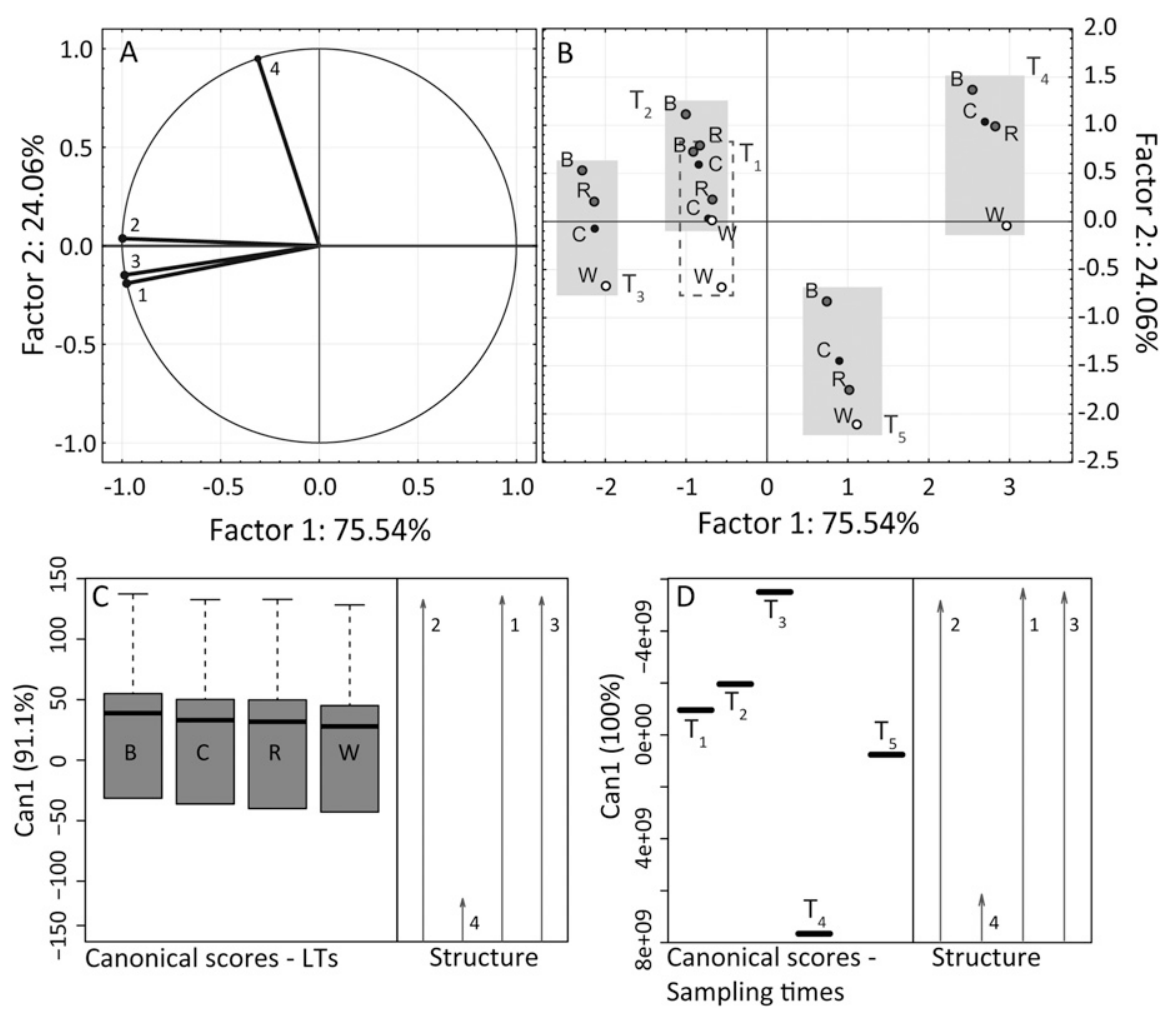

Fig. 5. Multivariate analysis between temperature gradients and light treatments in the different sampling times, in the field. (A) Principal component analysis performed for temperature gradients 1, 2, 3, and 4. Each gradient is represented by a vector and its direction indicates the variable contribution to the two principal factors; the closer the vector to the factor axis, the greater its contribution to determine the principal component. (B) Canonical component analysis of light treatments in each sampling time, derived by the principal component analysis. (C) Discriminant correspondence analysis of the effect of temperature gradients (variables), represented by arrows, on light treatments (LTs) (box plots); the discriminating power of each variable is confirmed if its arrow is elongated and if the box plots follow its direction. (D) Discriminant correspondence analysis of the effect of temperature gradients (variables), represented by arrows, on sampling times; the discriminating power of each variable is confirmed if its arrow is elongated and if the sampling times follow its direction.
Carbohydrate quantification. The same day when applying the LTs (20 Dec. 2017), 10 one-year-old shoots, with an apical flower bud, were collected randomly in the field and analyzed for the content of starch and soluble sugars. This represented $\mathrm{T}_{0}$. After the onset of light modification, carbohydrate quantification was carried out five times: on 31 Jan. $2018\left(\mathrm{~T}_{1}\right)$; on 6, 16, and 28 Mar. $2018\left(\mathrm{~T}_{2}, \mathrm{~T}_{3}\right.$, and $\left.\mathrm{T}_{4}\right)$; and on 4 Apr. $2018\left(\mathrm{~T}_{5}\right)$. For each timing, five shoots per LT were collected randomly.

The method of Leyva et al. (2008) was used for carbohydrate determination modified as follows. Bark and wood were separated, then dried at $70{ }^{\circ} \mathrm{C}$ for $48 \mathrm{~h}$ before being ground into a fine and homogeneous powder. Three technical replications were obtained from the powder of each sample. Soluble carbohydrates were extracted by incubating $25 \pm 4 \mathrm{mg}$ of dry material in $1 \mathrm{~mL}$ of acetate buffer ( $\mathrm{pH} \mathrm{5.5)}$ ) for $15 \mathrm{~min}$ at $70{ }^{\circ} \mathrm{C}$, followed by centrifuging for $10 \mathrm{~min}$ at 15,000 rpm. The supernatant was diluted 1:20 and quantified using anthrone as a reagent $[0.1 \%$ $(\mathrm{m} / \mathrm{v})$ in $98 \%$ sulfuric acid] by reading absorbance at $620 \mathrm{~nm}\left(\mathrm{~A}_{620}\right.$, Multiskan; Thermo Scientific, Waltham, MA). The remaining pellet was further processed to determine concentrations of starch. The pellet was exposed to $100{ }^{\circ} \mathrm{C}$ for $15 \mathrm{~min}$ and submitted to enzymatic digestion for $4 \mathrm{~h}$, with $50 \mu \mathrm{L}$ of $\alpha$-amylase $(0.25 \mathrm{U})$ and $50 \mu \mathrm{L}$ of amyloglucosidase $(1 \mathrm{U})$, at $37^{\circ} \mathrm{C}$. Once the digestion was completed, the samples were centrifuged for $10 \mathrm{~min}$ at $15,000 \mathrm{rpm}$, the supernatant was diluted 1:20 and quantified using the method described previously.

In total, four carbohydrate classes were quantified: wood soluble carbohydrates (WSC), wood starch (WS), bark soluble carbohydrates (BSC), and bark starch (BS).

Statistical analysis. Spectral transmittance variance analysis of the four LTs was performed for four bands of the spectrum: ultraviolet $(300-380 \mathrm{~nm})$, PAR (380-700 $\mathrm{nm})$, far red (FR) $(700-750 \mathrm{~nm})$, and NIR (750-900 nm). Means were separated by using the Student-Newman-Keuls (SNK) test $(P<0.05)$.

Variability of air and stem temperature was analyzed by analysis of covariance, using a mixed effect model: the net color was considered a fixed effect, the tree and the branch were considered random effects, and radiation and environmental air temperature were used as covariates. Differences among least square means were considered significant when applying $P<0.05$, using Student's $t$ test.

A two-way analysis of variance (ANOVA) was performed for phenology analysis and means were separated using the SNK test $(P<0.05)$, using Student's $t$ test. The same kind of analysis was used for evaluating differences in translocation of carbohydrates among the four LTs in each sampling time.

To evaluate possible effects of temperature gradients on carbohydrate dynamics, among the four LTs, during the sampling times, a multivariate analysis was performed. 
Temperature gradients were obtained by averaging the hourly temperature values of the $3 \mathrm{~d}$ before each sampling date. The selected gradients were between the following:

- Soil and air temperatures (1)

- Soil and air $_{\mathrm{LT}}$ temperatures (2)

- Soil and stem LT $_{\text {temperatures (3) }}$

- Stem LT $_{\text {and }}$ air $_{\mathrm{LT}}$ temperatures (4)

The environmental and biological variables, sampling times, and carbohydrate classes, respectively, were analyzed separately, through a principal component analysis. A canonical correlation analysis followed, where the single interactions of LTs and sampling times were displayed. To evaluate the single LTs, the effect of temperature gradients and the distribution of carbohydrate classes were analyzed with a discriminant correspondence analysis (DCA), separately.

\section{Laboratory trial}

Treatments and laboratory conditions. On 28 Feb. 2018, apple cuttings were collected randomly from the field (see field trial),
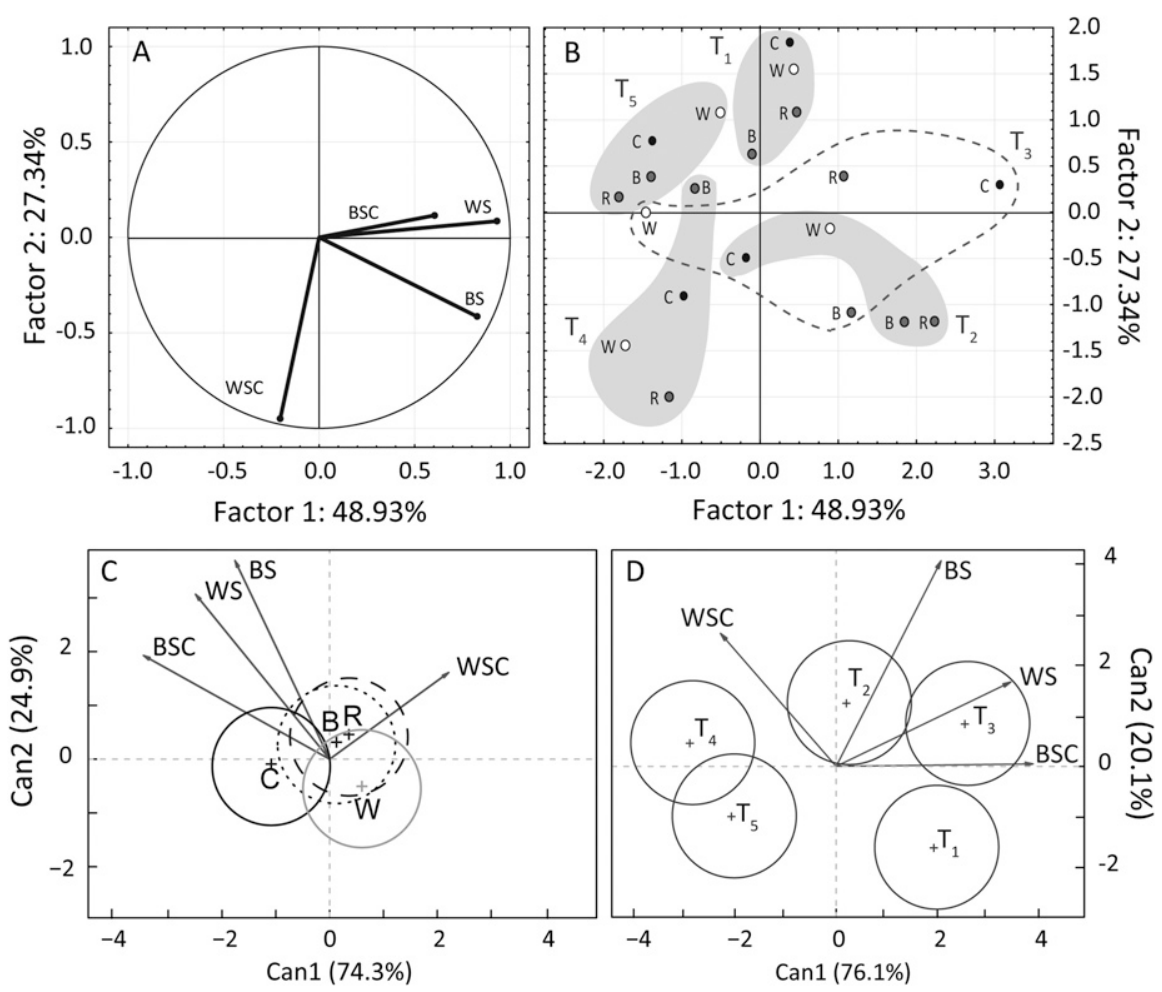

Fig. 6. Multivariate analysis between carbohydrate classes and light treatments (LTs) at the different sampling times, in the field. (A) Principal component analysis performed for carbohydrate classes including wood soluble carbohydrate (WSC), bark soluble carbohydrate (BSC), wood starch (WS), and bark starch (BS). Each variable is represented by a vector and its direction and length indicates the variables contribution to the two principal factors; the longer and closer the vector is to the factor axis, the greater the contribution to determine the principal component. (B) Canonical component analysis of LTs in each sampling time, derived by the principal component analysis. (C) Discriminant correspondence analysis of the effect of carbohydrate classes (variables), represented by arrows, on LTs (circles); the discriminating power of each variable is confirmed if its arrow is elongated and if the circle follows its line and direction. (D) Discriminant correspondence analysis of the effect of carbohydrate classes (variables), represented by arrows, on sampling times (circles); the discriminating power of each variable is confirmed if its arrow is elongated and if the circle follows its line and direction. bearing an apical flower bud. The chosen cuttings belonged to trees that were not influenced by the field trial. This period corresponded to $\approx 1280$ accumulated CU and $\approx 1030$ accumulated DDs. In the laboratory, the cuttings were shortened to $10 \mathrm{~cm}$ and placed in plastic tubes with $8 \mathrm{~mL}$ of tap water. Then the cuttings were placed in three boxes covered by patches of the white (W), blue (B), and red (R) nets, previously described, under a white neon lamp permanently left on (F32T8/TL741, 700 series, 32 W; Philips, Amsterdam, The Netherlands), in a controlled environment, where temperature and relative humidity were held at 22 to $23{ }^{\circ} \mathrm{C}$ and $30 \%$, respectively. Ten cuttings were put aside for immediate carbohydrate quantification, serving as $T_{0}$, leaving in each box 20 cuttings. Every 2 to $3 \mathrm{~d}$, bud phenology was monitored, following the BBCH scale (Meier et al., 1994). When cuttings reached certain key phenological stages, five were harvested for quantification of carbohydrates in the upper and lower parts. The key phenological stages selected were as follows: "green bud stage" $\left(\mathrm{T}_{1}\right)$ and "first flowers open" $\left(\mathrm{T}_{2}\right)$ [nos. 56 and 60, respectively, $\mathrm{BBCH}$ scale (Meier et al., 1994)]. The final sampling occurred on 3 Apr. 2018, before bloom $\left(\mathrm{T}_{\mathrm{F}}\right)$.

Spectra between 360 and $780 \mathrm{~nm}$ for each box were assessed by a CL-500A spectrophotometer (Konica Minolta, Chiyoda, Tokyo, Japan). In addition to the three colors, an empty one was assessed as reference. Irradiance values $\left(\mathrm{W} \cdot \mathrm{m}^{-2}\right)$ were converted to $\mu \mathrm{mol} \cdot \mathrm{m}^{-2} \cdot \mathrm{s}^{-1}$; transmittance could then be obtained as the ratio between the empty box readings and those for each colored box, which were then expressed as percentage.

Carbohydrate quantification. On reaching each key phenological stage, five cuttings were collected from each box, to determine carbohydrate amounts in the wood and the bark. Each cutting was divided in lower and upper parts; buds were removed to restrict the analysis to the reserve and transport compartments. Wood and bark were separated, then dried at $70{ }^{\circ} \mathrm{C}$ for $48 \mathrm{~h}$. The method used for quantifying the amount of soluble carbohydrates and starch was the same as that used in the field trials.

Statistical analysis. Two-way ANOVA was performed to test differences in the 400- to 700-nm and 700- to 715-nm ranges, among colored boxes; to detect differences in phenology evolution during time, among

Table 2. Temperature gradient values, for each light treatment, at the different sampling times.

\begin{tabular}{|c|c|c|c|c|c|c|c|c|c|c|c|c|c|}
\hline \multirow{4}{*}{ Sampling times } & \multicolumn{13}{|c|}{ Temperature gradients $\left({ }^{\circ} \mathrm{C}\right)$} \\
\hline & 1 & \multicolumn{4}{|c|}{2} & \multicolumn{4}{|c|}{3} & \multicolumn{4}{|c|}{4} \\
\hline & \multirow{2}{*}{ Soil-air } & \multicolumn{4}{|c|}{ Soil-air $_{\text {LT }}$} & \multicolumn{4}{|c|}{ Soil-stem $_{L T}$} & \multicolumn{4}{|c|}{ Stem $_{L T}-$ air $_{\mathrm{LT}}$} \\
\hline & & \multicolumn{12}{|c|}{ Light treatments } \\
\hline$\overline{\mathrm{T}_{1}}$ & 0.36 & 2.73 & 3.12 & 2.63 & 2.85 & 2.87 & 3.04 & 3.16 & 3.07 & -0.14 & 0.07 & -0.53 & -0.22 \\
\hline $\mathrm{T}_{2}$ & 0.82 & 2.70 & 3.00 & 2.53 & 2.76 & 2.59 & 2.75 & 2.75 & 2.73 & 0.11 & 0.25 & -0.22 & 0.03 \\
\hline $\mathrm{T}_{3}$ & 2.45 & 4.38 & 4.62 & 4.23 & 4.42 & 4.41 & 4.51 & 4.63 & 4.56 & -0.03 & 0.11 & -0.40 & -0.15 \\
\hline
\end{tabular}

$\mathrm{T}_{1}$ stands for 31 Jan.; $\mathrm{T}_{2}$ for 6 Mar.; $\mathrm{T}_{3}$ for 16 Mar.; $\mathrm{T}_{4}$ for 28 Mar.; $\mathrm{T}_{5}$ for 4 Apr. 2018. $\mathrm{B}=$ blue; $\mathrm{C}=$ control; $\mathrm{R}=$ red; $\mathrm{W}=$ white. 
LTs; and for detecting variations of soluble carbohydrates and starch, taking into consideration sampling times, LTs, and the location of sampling.

All the generated means were separated using the SNK test $(P<0.05)$.

\section{Results and Discussion}

Field trial. The presence of colored nets influenced air temperature, especially under $\mathrm{B}$ and $\mathrm{W}$ nets, the first being significantly colder than the latter, even if the average seasonal difference is less than $0.5{ }^{\circ} \mathrm{C}$ (Table 1). Such a variation could be related to the spectral properties of the nets (Fig. 2). The two treatments have statistically contrasting transmission of ultraviolet, $P A R$, and FR, although these wavebands are not re-

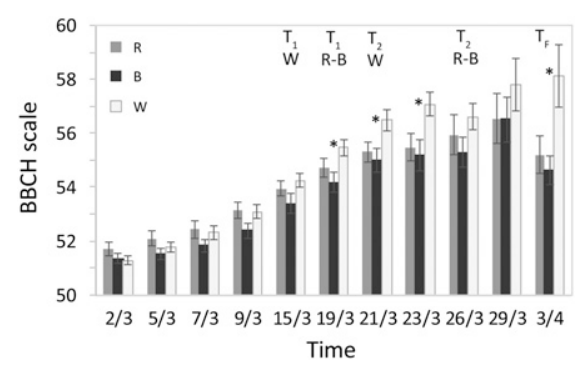

Fig. 7. Flower bud phenology evolution inside the boxes; the presence of asterisks indicates significant differences at $P<0.05$. T1 represents the first key phenological stage (no. 56, i.e., green bud stage); $\mathrm{T} 2$ represents the second key phenological stage (no. 60, i.e., first flowers open); and TF represents the end of the trial. sponsible for heat radiation. Solar radiation is indeed influencing the thermal properties of the LTs, although in a smaller degree than those above 900 to $1000 \mathrm{~nm}$. Higher temperatures under a white compared with a blue net have been reported throughout the year, except for winter (Basile et al.,2014). On the other hand, no differences were found in both air temperature and the amount of scattered light (Kalcsits et al., 2017; Rajapakse and Shahak, 2007).

Despite that LTs influenced temperatures, no difference was detected in bud phenology (Fig. 3), thus all trees bloomed approximately the middle of April (data not shown). Although there were significant differences in carbohydrate dynamics (Fig. 4), the photoselective nets did not appear to have strong impacts on such translocations. In fact, temperature gradient $4\left(\right.$ stem $\left._{\mathrm{LT}}-\mathrm{air}_{\mathrm{LT}}\right)$ was explaining only $24 \%$ (Fig. $5 \mathrm{~A}$ ) and the dynamics of carbohydrate classes among LTs (Fig. 6A) did not have such a marked distribution, with the strongest factor explaining less than $50 \%$. The consistent groupings based on sampling times (Figs. 5B and 6B), the similar canonical scores involving LTs (Fig. 5C), and their strong clustering (Fig. 6C) further explain the low influence that spectrum had. This may be justified by the fact that, although the single tree was displaying different spectra (Fig. 1), the effect was not strong enough to have an impact in the single sections. Phenology evolution did not seem to be primarily controlled by the buds, rather than by a central system in the tree, such as the hormonal component (Zhuang et al., 2015), which was not influ- enced by the LTs. The main reason may be found below the ground (Dong et al., 2001; Greer et al., 2006). The temperature gradients including soil $(1,2$, and 3; Table 2) were primarily dictating carbohydrate dynamics (Fig. 5A-D), even though this observation may be purely correlative, as no attempt was made to modify soil temperature. However, when soil temperature was higher than the air, especially during $T_{2}$ and $T_{3}$ (Table 2), there appeared to be higher amounts of starch, in both wood and bark (Fig. 6B-D), in agreement with Zwieniecki et al. (2015). On the contrary, when soil temperature was lower than the air, at $\mathrm{T}_{4}$, a conversion from nonsoluble to soluble carbohydrates in the wood had probably occurred (Fig. 6B), as stated in literature (Gordon and Dejong, 2007; Zwieniecki et al., 2015), an essential passage in exiting dormancy and activating budbreak (Park et al., 2009; Signorelli et al., 2018).

Thus, stronger differences in translocation of carbohydrates were more evident among sampling times, which were characterized by different temperature gradients (Figs. 5D and 6B). DCA in Fig. 6D shows that the circles defining sampling times are standing apart, explaining more than $75 \%$, compared with those representing LTs (Fig. 6C). However, $\mathrm{T}_{5}$ especially seemed to have lower quantities of all carbohydrates (Fig. 4). It is possible that intense metabolic activities were ongoing, as full bloom would have occurred soon after, thus the trees might have been experiencing a depletion of carbohydrates and were in need of sugar remobilization from the lower portions, for budbreak

Table 3. Variations of soluble carbohydrates and starch during time, for each type of sample and its location, among the light treatments (LTs), in the laboratory.

\begin{tabular}{|c|c|c|c|c|c|c|c|c|c|c|c|c|c|c|c|c|c|c|}
\hline$\overline{\text { Time }}$ & $\mathrm{T}_{1}$ & & & $\mathrm{~T}_{2}$ & & & $\mathrm{~T}_{\mathrm{F}}$ & & & $\mathrm{T}_{1}$ & & & $\mathrm{~T}_{2}$ & & & $\mathrm{~T}_{\mathrm{F}}$ & & \\
\hline Location & Down & & & Down & & & Down & & & Up & & & Up & & & Up & & \\
\hline Sample $\left(\mathrm{mg} \cdot \mathrm{g}^{-1} \mathrm{DW}\right)$ & BSC & & & BSC & & & BSC & & & BSC & & & BSC & & & BSC & & \\
\hline \multirow[t]{3}{*}{ LTs } & $\mathrm{R}$ & 57.30 & $\mathrm{a}$ & $\mathrm{R}$ & 49.12 & $\mathrm{~b}$ & $\mathrm{R}$ & 49.63 & $\mathrm{a}$ & $\mathrm{R}$ & 70.88 & $\mathrm{a}$ & $\mathrm{R}$ & 58.86 & $\mathrm{a}$ & $\mathrm{R}$ & 53.50 & $\mathrm{a}$ \\
\hline & $\mathrm{B}$ & 54.79 & $\mathrm{a}$ & $\mathrm{B}$ & 45.69 & $\mathrm{~b}$ & B & 46.58 & $\mathrm{~b}$ & $\mathrm{~B}$ & 65.47 & $\mathrm{ab}$ & B & 52.74 & b & $\mathrm{B}$ & 51.97 & $\mathrm{a}$ \\
\hline & W & 52.60 & $\mathrm{a}$ & $\mathrm{W}$ & 64.05 & $\mathrm{a}$ & W & 44.73 & $\mathrm{~b}$ & $\mathrm{~W}$ & 59.78 & $\mathrm{~b}$ & W & 63.68 & $\mathrm{a}$ & $\mathrm{W}$ & 51.80 & $\mathrm{a}$ \\
\hline Sample (mg.g $\left.{ }^{-1} \mathrm{DW}\right)$ & BS & & & BS & & & BS & & & BS & & & BS & & & BS & & \\
\hline \multirow[t]{3}{*}{ LTs } & $\mathrm{R}$ & 9.06 & $\mathrm{a}$ & $\mathrm{R}$ & 6.47 & $\mathrm{a}$ & $\mathrm{R}$ & 3.55 & $\mathrm{~b}$ & $\mathrm{R}$ & 8.51 & $\mathrm{a}$ & $\mathrm{R}$ & 2.29 & b & $\mathrm{R}$ & 3.68 & $\mathrm{~b}$ \\
\hline & $\mathrm{B}$ & 8.49 & $\mathrm{a}$ & $\mathrm{B}$ & 6.31 & $\mathrm{a}$ & B & 3.37 & $\mathrm{~b}$ & $\mathrm{~B}$ & 10.96 & $\mathrm{a}$ & B & 5.31 & $\mathrm{~b}$ & $\mathrm{~B}$ & 3.40 & $\mathrm{~b}$ \\
\hline & $\mathrm{W}$ & 9.59 & $\mathrm{a}$ & $\mathrm{W}$ & 8.84 & $\mathrm{a}$ & $\mathrm{W}$ & 8.60 & $\mathrm{a}$ & $\mathrm{W}$ & 11.73 & $\mathrm{a}$ & $\mathrm{W}$ & 14.32 & $\mathrm{a}$ & $\mathrm{W}$ & 7.14 & $\mathrm{a}$ \\
\hline Time & $\mathrm{T}_{1}$ & & & $\mathrm{~T}_{2}$ & & & $\mathrm{~T}_{\mathrm{F}}$ & & & $\mathrm{T}_{1}$ & & & $\mathrm{~T}_{2}$ & & & $\mathrm{~T}_{\mathrm{F}}$ & & \\
\hline Location & Down & & & Down & & & Down & & & Up & & & $\mathrm{Up}$ & & & Up & & \\
\hline Sample (mg.g ${ }^{-1}$ DW) & WSC & & & WSC & & & WSC & & & WSC & & & WSC & & & WSC & & \\
\hline \multirow[t]{3}{*}{ LTs } & $\mathrm{R}$ & 38.09 & $\mathrm{a}$ & $\mathrm{R}$ & 24.81 & $\mathrm{~b}$ & $\mathrm{R}$ & 22.57 & $\mathrm{a}$ & $\mathrm{R}$ & 34.53 & $\mathrm{ab}$ & $\mathrm{R}$ & 22.30 & $\mathrm{a}$ & $\mathrm{R}$ & 18.70 & $\mathrm{a}$ \\
\hline & $\mathrm{B}$ & 31.91 & $\mathrm{a}$ & $\mathrm{B}$ & 20.91 & $\mathrm{~b}$ & B & 14.69 & $\mathrm{~b}$ & $\mathrm{~B}$ & 29.30 & $\mathrm{~b}$ & B & 21.94 & $\mathrm{a}$ & $\mathrm{B}$ & 19.96 & $\mathrm{a}$ \\
\hline & W & 38.37 & $\mathrm{a}$ & $\mathrm{W}$ & 34.87 & $\mathrm{a}$ & W & 13.82 & $\mathrm{~b}$ & $\mathrm{~W}$ & 42.38 & $\mathrm{a}$ & $\mathrm{W}$ & 38.77 & $\mathrm{a}$ & W & 20.91 & $\mathrm{a}$ \\
\hline Sample (mg.g $\left.{ }^{-1} \mathrm{DW}\right)$ & WS & & & WS & & & WS & & & WS & & & WS & & & WS & & \\
\hline \multirow[t]{3}{*}{ LTs } & $\mathrm{R}$ & 22.06 & $\mathrm{a}$ & $\mathrm{R}$ & 7.19 & $\mathrm{~b}$ & $\mathrm{R}$ & 11.01 & $\mathrm{a}$ & $\mathrm{R}$ & 12.81 & $\mathrm{ab}$ & $\mathrm{R}$ & 8.87 & $b$ & $\mathrm{R}$ & 9.59 & $\mathrm{a}$ \\
\hline & B & 14.72 & $\mathrm{a}$ & $\mathrm{B}$ & 13.41 & $\mathrm{a}$ & B & 2.20 & $\mathrm{~b}$ & B & 10.49 & $\mathrm{~b}$ & B & 13.37 & b & B & 4.21 & $\mathrm{a}$ \\
\hline & $\mathrm{W}$ & 20.48 & $\mathrm{a}$ & $\mathrm{W}$ & 15.29 & $\mathrm{a}$ & W & 5.28 & $a b$ & W & 21.41 & $\mathrm{a}$ & W & 22.87 & $a$ & W & 9.64 & $\mathrm{a}$ \\
\hline
\end{tabular}

$\mathrm{T}_{0}$ represents the beginning of the trial; $\mathrm{T}_{1}$ represents the time when the first key phenological stage was reached (no. 56 , i.e., green bud stage); $\mathrm{T}_{2}$ represents the second key phenological stage (no. 60, i.e., first flowers open); $\mathrm{T}_{\mathrm{F}}$ represents the end of the trial. Different letters, within columns, indicate significant differences at $P<0.05$, using Student's $t$ test. $\mathrm{R}=$ red; $\mathrm{B}=$ blue; $\mathrm{W}=$ white; $\mathrm{BSC}=$ bark soluble carbohydrates; $\mathrm{WSC}=$ wood soluble carbohydrates; $\mathrm{BS}=$ bark starch; WS $=$ wood starch.

Table 4. Photosynthetically active radiation $(P A R)$ and far-red (FR) average transmittance values inside the colored boxes.

\begin{tabular}{|c|c|c|c|c|c|c|}
\hline Light treatments & $P A R(400-700 \mathrm{~nm})(\%)$ & $\mathrm{SE}$ & & FR $(700-715 \mathrm{~nm})(\%)$ & $\mathrm{SE}$ & \\
\hline$\overline{\operatorname{Red}}$ & 67.1 & \pm 1.039 & $\mathrm{~b}$ & 85.7 & \pm 1.418 & $\bar{a}$ \\
\hline Blue & 61.4 & \pm 0.895 & $\mathrm{c}$ & 54.5 & \pm 0.875 & $\mathrm{~b}$ \\
\hline White & 85.9 & \pm 1.090 & $\mathrm{a}$ & 85.5 & \pm 1.022 & $\mathrm{a}$ \\
\hline
\end{tabular}

Different letters, within columns, represent significant difference at $P<0.05$, using Student's $t$ test. 
Table 5. Variations of soluble carbohydrates and starch, for each light treatment (LT), type of sample, and its location, during time in the laboratory.

\begin{tabular}{|c|c|c|c|c|c|c|c|c|c|c|c|c|}
\hline$\overline{\mathrm{LT}}$ & $\mathrm{R}$ & & & $\mathrm{R}$ & & & $\mathrm{R}$ & & & $\mathrm{R}$ & & \\
\hline Location & Down & & & Up & & & Down & & & Up & & \\
\hline \multirow[t]{3}{*}{ Timings } & $\mathrm{T}_{0}$ & 55.35 & $a b$ & $\mathrm{~T}_{0}$ & 66.75 & $\mathrm{a}$ & $\mathrm{T}_{0}$ & 105.26 & $\mathrm{a}$ & $\mathrm{T}_{0}$ & 132.94 & $\mathrm{a}$ \\
\hline & $\mathrm{T}_{1}$ & 57.30 & $\mathrm{a}$ & $\mathrm{T}_{1}$ & 70.88 & $\mathrm{a}$ & $\mathrm{T}_{1}$ & 38.09 & $\mathrm{~b}$ & $\mathrm{~T}_{1}$ & 34.53 & $\mathrm{~b}$ \\
\hline & $\mathrm{T}_{\mathrm{F}}$ & 49.12 & $\mathrm{~b}$ & $\mathrm{~T}_{\mathrm{F}}$ & 53.50 & $\mathrm{c}$ & $\mathrm{T}_{\mathrm{F}}$ & 22.57 & $\mathrm{~b}$ & $\mathrm{~T}_{\mathrm{F}}$ & 20.91 & $\mathrm{~b}$ \\
\hline Sample $\left(\mathrm{mg} \cdot \mathrm{g}^{-1} \mathrm{DW}\right)$ & BS & & & BS & & & WS & & & WS & & \\
\hline \multirow[t]{2}{*}{ Timings } & $\mathrm{T}_{0}$ & 23.29 & $\mathrm{a}$ & $\mathrm{T}_{0}$ & 25.34 & $\mathrm{a}$ & $\mathrm{T}_{0}$ & 124.31 & $\mathrm{a}$ & $\mathrm{T}_{0}$ & 136.84 & $\mathrm{a}$ \\
\hline & $\mathrm{T}_{\mathrm{F}}$ & 3.55 & $\mathrm{c}$ & $\mathrm{T}_{\mathrm{F}}$ & 3.80 & $\mathrm{c}$ & $\mathrm{T}_{\mathrm{F}}$ & 12.86 & $\mathrm{~b}$ & $\mathrm{~T}_{\mathrm{F}}$ & 9.59 & $\mathrm{~b}$ \\
\hline LT & $\mathrm{B}$ & & & B & & & B & & & $\mathrm{B}$ & & \\
\hline Location & Down & & & Up & & & Down & & & Up & & \\
\hline Sample (mg. $\left.\mathrm{g}^{-1} \mathrm{DW}\right)$ & BSC & & & BSC & & & WSC & & & WSC & & \\
\hline \multirow[t]{2}{*}{ Timings } & $\mathrm{T}_{0}$ & 55.35 & $\mathrm{a}$ & $\mathrm{T}_{0}$ & 66.75 & $\mathrm{a}$ & $\mathrm{T}_{0}$ & 105.26 & $\mathrm{a}$ & $\mathrm{T}_{0}$ & 132.94 & $\mathrm{a}$ \\
\hline & $\mathrm{T}_{1}$ & 54.79 & $\mathrm{~b}$ & $\mathrm{~T}_{1}$ & 65.47 & $\mathrm{a}$ & $\mathrm{T}_{1}$ & 31.91 & $\mathrm{~b}$ & $\mathrm{~T}_{1}$ & 29.30 & $\mathrm{~b}$ \\
\hline \multirow{2}{*}{ Timings } & $\mathrm{T}_{2}$ & 7.41 & $\mathrm{~b}$ & $\mathrm{~T}_{2}$ & 5.31 & $\mathrm{c}$ & $\mathrm{T}_{2}$ & 13.41 & $\mathrm{~b}$ & $\mathrm{~T}_{2}$ & 13.37 & $\mathrm{~b}$ \\
\hline & $\mathrm{T}_{\mathrm{F}}$ & 4.46 & $\mathrm{~b}$ & $\mathrm{~T}_{\mathrm{F}}$ & 4.39 & $\mathrm{c}$ & $\mathrm{T}_{\mathrm{F}}$ & 2.97 & $\mathrm{~b}$ & $\mathrm{~T}_{\mathrm{F}}$ & 5.92 & $\mathrm{~b}$ \\
\hline LT & W & & & W & & & $\mathrm{W}$ & & & W & & \\
\hline Location & Down & & & Up & & & Down & & & Up & & \\
\hline Sample (mg.g $\left.{ }^{-1} \mathrm{DW}\right)$ & $\mathrm{BSC}$ & & & $\mathrm{BSC}$ & & & WSC & & & WSC & & \\
\hline \multirow[t]{4}{*}{ Timings } & $\mathrm{T}_{0}$ & 55.35 & $\mathrm{~b}$ & $\mathrm{~T}_{0}$ & 66.75 & $\mathrm{a}$ & $\mathrm{T}_{0}$ & 105.26 & $\mathrm{a}$ & $\mathrm{T}_{0}$ & 132.94 & $\mathrm{a}$ \\
\hline & $\mathrm{T}_{1}$ & 52.60 & $\mathrm{~b}$ & $\mathrm{~T}_{1}$ & 57.78 & $\mathrm{~b}$ & $\mathrm{~T}_{1}$ & 38.37 & $\mathrm{~b}$ & $\mathrm{~T}_{1}$ & 42.38 & $\mathrm{~b}$ \\
\hline & $\mathrm{T}_{2}$ & 64.05 & $\mathrm{a}$ & $\mathrm{T}_{2}$ & 63.68 & $a b$ & $\mathrm{~T}_{2}$ & 34.87 & $\mathrm{~b}$ & $\mathrm{~T}_{2}$ & 38.77 & $\mathrm{~b}$ \\
\hline & $\mathrm{T}_{\mathrm{F}}$ & 44.73 & $\mathrm{c}$ & $\mathrm{T}_{\mathrm{F}}$ & 51.79 & $\mathrm{c}$ & $\mathrm{T}_{\mathrm{F}}$ & 13.82 & $\mathrm{c}$ & $\mathrm{T}_{\mathrm{F}}$ & 18.70 & $\mathrm{~b}$ \\
\hline Sample $\left(\mathrm{mg} \cdot \mathrm{g}^{-1} \mathrm{DW}\right)$ & BS & & & BS & & & WS & & & WS & & \\
\hline \multirow[t]{3}{*}{ Timings } & $\mathrm{T}_{0}$ & 23.29 & $\mathrm{a}$ & $\mathrm{T}_{0}$ & 25.34 & a & $\mathrm{T}_{0}$ & 124.31 & $\mathrm{a}$ & $\mathrm{T}_{0}$ & 136.84 & $\mathrm{a}$ \\
\hline & $\mathrm{T}_{1}$ & 9.59 & $\mathrm{~b}$ & $\mathrm{~T}_{1}$ & 11.73 & $\mathrm{~b}$ & $\mathrm{~T}_{1}$ & 20.48 & $\mathrm{~b}$ & $\mathrm{~T}_{1}$ & 21.41 & $\mathrm{~b}$ \\
\hline & $\mathrm{T}_{2}$ & 8.84 & $\mathrm{~b}$ & $\mathrm{~T}_{2}$ & 14.32 & $\mathrm{~b}$ & $\mathrm{~T}_{2}$ & 15.29 & $\mathrm{~b}$ & $\mathrm{~T}_{2}$ & 22.87 & $\mathrm{~b}$ \\
\hline
\end{tabular}

$\mathrm{T}_{0}$ represents the beginning of the trial; $\mathrm{T}_{1}$ represents the time when the first key phenological stage was reached (no. 56, i.e., green bud stage); $\mathrm{T}_{2}$ represents the second key phenological stage (no. 60, i.e., first flowers open); $\mathrm{T}_{\mathrm{F}}$ represents the end of the trial. Different letters, within columns, indicate significant differences at $P<0.05$, using Student's $t$ test. $\mathrm{R}=$ red; $\mathrm{B}=$ blue; $\mathrm{W}=$ white; $\mathrm{BSC}=$ bark soluble carbohydrates; $\mathrm{WSC}=$ wood soluble carbohydrates; $\mathrm{BS}=$ bark starch; $\mathrm{WS}=$ wood starch.

(Bazot et al., 2013; Dietze et al., 2014; Hartmann and Trumbore, 2016; Tixier et al., 2017a, 2017b). Such consideration may explain why $\mathrm{T}_{5}$ was not particularly influenced by any of the temperature gradients (Figs. 5B-D and 6B-D). Based on these results, influencing the light microenvironment of only a section of canopy is not going to impact sugar remobilization. Although there will be different temperature gradients between soil and air inside the nets, the whole tree appears, all the same, to behave as a single structure, balancing the general response. Therefore, the single buds do not seem to be solely controlling and determining the translocation activity. To generate clear differences in transport and remobilization, the soil and root apparatus and, or, other parts, such as the trunk, or the canopy, should be subjected to a treatment strong enough to significantly influence stem temperature (Tixier et al., 2017b). As photoselective nets have shown to alter soil temperature (Kalcsits et al., 2017), and as apple phenology is known to be influenced by root-zone temperatures (Dong et al., 2001; Greer et al., 2006), the application of these nets during winter and early spring could modify the inner metabolic processes of the tree and modify tree responses (Loescher et al., 1990; Ruiz et al., 2005).

Laboratory trial. Variation and translocation of carbohydrates in the laboratory trial was more in line with the phenology evolution. By completely isolating the cuttings and keeping them in an air-controlled environment, it was possible to exclude the soil effect, thus possible temperature gradients. In these normalized conditions, clear differences in phenology were seen, where W anticipated both the phenological key stages (Fig. 7) and tended to have higher amounts of carbohydrates, when there were statistical differences among LTs (Table 3). This LT might have anticipated the other two because of the different light environment. Light spectrum results and analysis (Fig. 8, Table 4) showed significantly higher transmission of $P A R$ and FR. Regarding the transmission of FR (700-715 nm), W had a significantly higher percentage, compared with $\mathrm{R}$, whereas $\mathrm{B}$ was transmitting the lowest (Table 4). The possible activation of photoreceptors dedicated to budbreak and bloom might be influenced by this waveband range. Studies demonstrated how bloom could be promoted by irradiation with FR light (700 $740 \mathrm{~nm}$ ) (Bagnall et al., 1995; Björn, 2015;
Goto et al., 1991; Lin, 2000). On the other hand, poor FR light in combination with blue light applications delayed flowering (Guo et al., 1998; Halliday et al., 1994). A highly suitable explanation for anticipated bloom in FR-enriched environments (i.e., the perceiving of shade of a nearby competitor) would allow the plant to fasten its phenology, to achieve as much light as possible (Devlin et al., 1999; Yuan et al., 2017), although this happened in $\mathrm{W}$ but not in R cuttings, where FR was higher in both boxes (Table 4). It could be speculated that higher PAR transmission in the $\mathrm{W}$ box may have, also, taken part in influencing $\mathrm{W}$ bud phenology.

Even though there was a delay of $\mathrm{R}$ and $\mathrm{B}$ boxes in phenological evolution, carbohydrates were nevertheless consumed (Table 5). At $\mathrm{T}_{\mathrm{F}}$, nearly half the amount of BS was found in R and B (an average of $4.2 \mathrm{mg} \mathrm{DW}$ ), compared with W cuttings (an average of $8.1 \mathrm{mg} \mathrm{DW}$ ), both in the lower and upper cutting sections (Table 3), thus starch had been consumed more quickly. In wood, W cuttings were significantly moving reserves upward (Table 6), unlike $\mathrm{R}$ and $\mathrm{B}$. This trial demonstrated the higher efficiency of the $\mathrm{W}$ treatment in managing carbohydrates while exiting dormancy, given a higher 
Table 6. Translocation of soluble carbohydrates and starch from the lower to the upper section of the cuttings, during time, for each type of sample, of each light treatment (LT), in the laboratory.

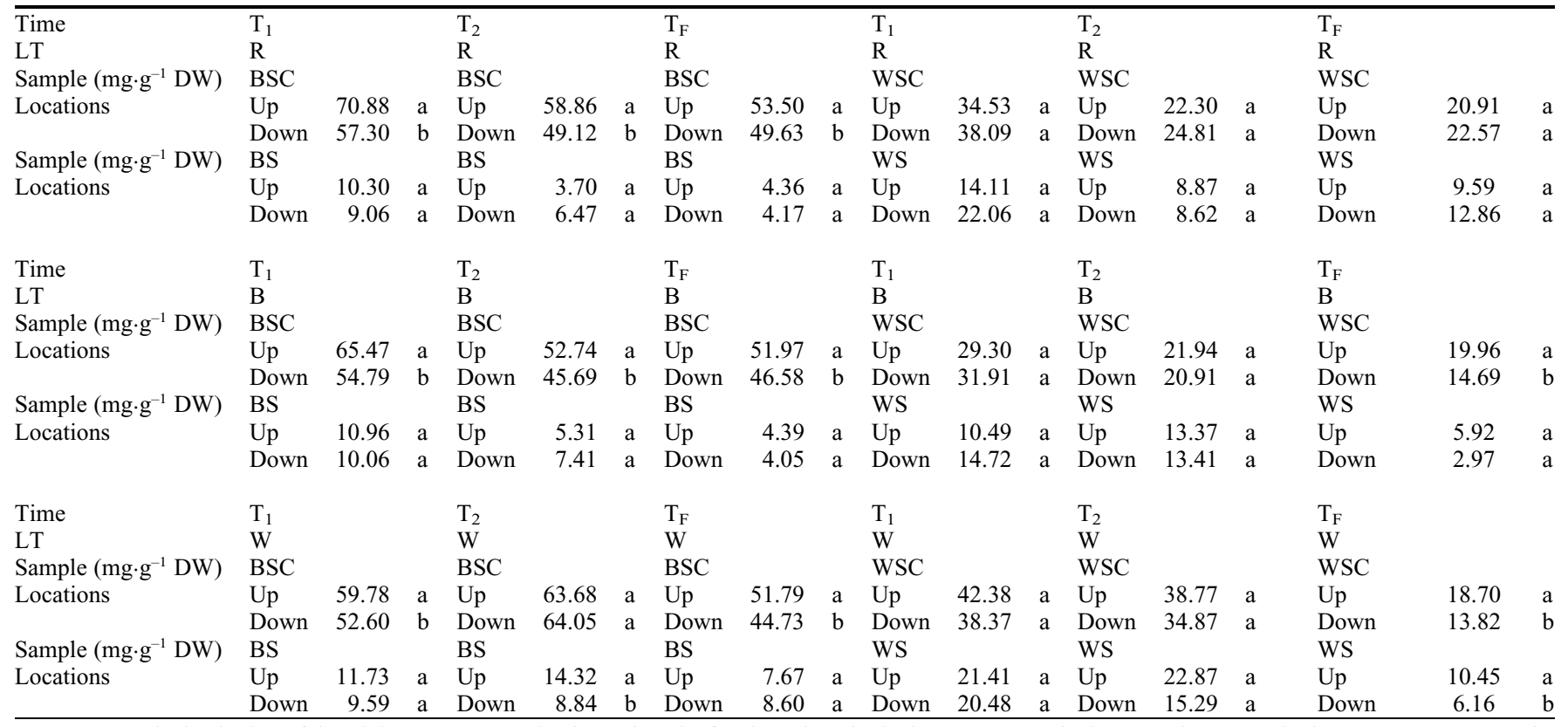

$\mathrm{T}_{0}$ represents the beginning of the trial; $\mathrm{T}_{1}$ represents the time when the first key phenological stage was reached (no. 56, i.e., green bud stage); $\mathrm{T}_{2}$ represents the second key phenological stage (no. 60, i.e., first flowers open); $\mathrm{T}_{\mathrm{F}}$ represents the end of the trial. Different letters, within columns, indicate significant differences at $P<0.05$, using Student's $t$ test. $\mathrm{R}=$ red; $\mathrm{B}=$ blue; $\mathrm{W}=$ white; $\mathrm{BSC}=$ bark soluble carbohydrates; $\mathrm{WSC}=$ wood soluble carbohydrates; $\mathrm{BS}=$ bark starch; $\mathrm{WS}=$ wood starch.



Fig. 8. Spectral (A) irradiance and (B) transmittance patterns inside the colored boxes, ranging from 400 to $720 \mathrm{~nm}$, of each light treatment in the laboratory.

amount of reserves at the end of the experiment (Table 3 ). In a wider scenery (like the field, for example), those extra reserves could potentially have been used for future needs. On the other hand, it demonstrated the lower efficiency of the B net, as this treatment had the lowest amount of carbohydrates in the lower parts of the cuttings, indicating it was using sugars for maintenance respiration. As growth resumes in spring, the general assumption is that there is a depletion in shoots and roots of carbohydrate reserves (Loescher et al., 1990), as demonstrated in many fruit species, such as apple (McQueen et al., 2004; Yoshioka et al., 1988), peach (Bonhomme et al., 2005), Japanese pear (Marafon et al., 2011), pistachio (Sperling et al., 2015), black currant (Pagter et al., 2015), sweet cherry (Kaufmann and Blanke, 2017), walnut
(Lacointe et al., 2004; Tixier et al., 2017a, $2017 \mathrm{~b}$ ), and forestry species (Hartmann and Trumbore, 2016; Loescher et al., 1990). This more pronounced depletion in B suggests a further remobilization of carbohydrates from the lower parts of the branch, the trunk, or roots, without dedicating sugars to exiting dormancy. Nevertheless, B could be useful, if the aim was to delay bloom for commercial purposes, such as to avoid late spring frosts, even at the cost of extra consumption of carbohydrates (i.e., poorer bud performance in fruit set). It has to be underlined that these are hypotheses deriving from results of a trial conducted in a controlled environment, where light was not representing the solar spectrum, and where air temperature was constant throughout the monitored period, in the absence of soil. Different findings may emerge when transferring this setup to the field. In fact, the possible (even slight) differences in canopy air temperature the LTs might provoke and their interactions with soil temperature, which also may be affected by LTs (Kalcsits et al., 2017), would possibly have consequences on the patterns of carbohydrate translocation and potentially on bud phenology. The two trials could bring interest on understanding the different ways an orchard could be managed, during the dormant phase.

Light spectrum manipulation influenced canopy air temperature during dormancy and budbreak; however, the experimental setup did not allow obtaining differences in carbohydrate dynamics among the different light environments. The complexity of the problem makes it difficult to carry out an experiment capable of removing the unwanted effects of tree and soil conditions at the same time. This may be tested in further studies; the solution chosen for this work would appear to be difficult to surpass under field conditions. To this extent, communication signals between the root apparatus and the canopy were not strongly influenced by the different spectra. As temperature gradients including soil appeared to have the highest impact on the translocation of sugars in the trees, it followed that flower bud phenology was not influenced by the different LTs. On the other hand, the results of the laboratory trial suggest the potential of photoselective nets to improve the efficiency, or modify the timings, of carbohydrate management and translocation in apple during ecodormancy and budbreak.

To expand our knowledge about fruit tree crops responses to light, the study of light 
manipulation in orchards, during phenological phases out of the ordinary, can give valuable information. Furthermore, possible practical applications in the field should not be excluded, allowing improvements of orchard management.

\section{Literature Cited}

Arthurs, S.P., R.H. Stamps, and F.F. Giglia. 2013. Environmental modification inside photoselective shadehouses. J. Amer. Soc. Hort. Sci. 48:975979, doi: 10.21273/HORTSCI.48.8.975.

Bagnall, D.J., R.W. King, G.C. Whitelam, M.T. Boylan, D. Wagner, and P.H. Quail. 1995. Flowering responses to altered expression of phytochrome in mutants and transgenic lines of Arabidopsis thaliana (L.) Heynh. Plant Physiol. 108:1495-1503, doi: 10.1104/pp.108.4.1495.

Basile, B., M. Giaccone, Y. Shahak, M. Forlani, and C. Cirillo. 2014. Regulation of the vegetative growth of kiwifruit vines by photo-selective anti-hail netting. Scientia Hort. 172:300-307, doi: 10.1016/j.scienta.2014.04.011.

Bazot, S., L. Barthes, D. Blanot, and C. Fresneau. 2013. Distribution of non-structural nitrogen and carbohydrate compounds in mature oak trees in a temperate forest at four key phenological stages. Trees (Berl.) 27:1023-1034, doi: 10.1007/s00468-013-0853-5.

Beppu, K., T. Suehara, and I. Kataoka. 2001. Embryo sac development and fruit set of 'Satohnishiki' sweet cherry as affected by temperature, $\mathrm{GA}_{3}$ and paclobutrazol. J. Jpn. Soc. Hort. Sci. 70(2):157-162.

Björn, L.O. 2015. Molecules and photochemical reactions in biological light perception and regulation, p. 151-167. In: L.O. Björn (ed.). Photobiology. The Science of Light and Life. 3rd ed. Springer, New York.

Bonhomme, M., R. Rageau, A. Lacointe, and M. Gendraud. 2005. Influences of cold deprivation during dormancy on carbohydrate contents of vegetative and floral primordia and nearby structures of peach buds (Prunus persica L. Batch). Scientia Hort. 105(2):223-240, doi: 10.1016/j.scienta.2005.01.015.

Bonhomme, M., M. Peuch, T. Ameglio, R. Rageau, A. Guilliot, M. Decourteix, G. Alves, S. Sakr, and A. Lacointe. 2010. Carbohydrate uptake from xylem vessels and its distribution among stem tissues and buds in walnut (Juglans regia L.). Tree Physiol. 30(1):89-102, doi: 10.1093/ treephys/tpp103.

Buchanan, D.W., J.F. Bartholic, and R.H. Biggs. 1977. Manipulation of bloom and ripening dates of three Florida grown peach and nectarine cultivars through sprinkling and shade. J. Amer. Soc. Hort. Sci. 102:466-470.

Campoy, J.A., D. Ruiz, and J. Egea. 2010. Effects of shading and thidiazuron + oil treatment on dormancy breaking, blooming and fruit set in apricot in a warm-winter climate. Scientia Hort. 125(3):203210, doi: 10.1016/j.scienta.2010.03.029.

Campoy, J.A., D. Ruiz, and J. Egea. 2011. Dormancy in temperate fruit trees in a global warming context: A review. Scientia Hort. 130:357-372, doi: 10.1016/j.scienta.2011.07.011.

Charrier, G., M. Poirier, M. Bonhomme, A. Lacointe, and T. Améglio. 2013. Frost hardiness in walnut trees (Juglans regia L.): How to link physiology and modelling? Tree Physiol. 33(11):1229-1241, doi: 10.1093/treephys/ tpt090.

Considine, M.J. and J.A. Considine. 2016. On the language and physiology of dormancy and quiescence in plants. J. Expt. Bot. 67:31893203, doi: 10.1093/ jxb/erw138.
Couvillon, G.A. and A. Erez. 1985. Influence of prolonged exposure to chilling temperatures on bud break and heat requirement for bloom of several fruit species. J. Amer. Soc. Hort. Sci. 110:47-50.

Coville, F.V. 1920. The influence of cold in stimulating the growth of plants. Proc. Natl. Acad. Sci. USA 6(7):434-435.

Devlin, P.F., P.R. Robson, S.R. Patel, L. Goosey, R.A. Sharrock, and G.C. Whitelam. 1999. Phytochrome D acts in the shade-avoidance syndrome in Arabidopsis by controlling elongation growth and flowering time. Plant Physiol. 119:909-915, doi: 10.1104/pp.119.3.909.

Dietze, M.C., A. Sala, M.S. Carbone, C.I. Czimczik, J.A. Mantooth, A.D. Richardson, and R. Vargas. 2014. Nonstructural carbon in woody plants. Annu. Rev. Plant Biol. 65:667-687, doi: 10.1146/annurev-arplant-050213-040054.

Dong, S., C.F. Scagel, L. Cheng, L.H. Fuchigami, and P.T. Rygiewicz. 2001. Soil temperature and plant growth stage influence nitrogen uptake and amino acid concentration of apple during early spring growth. Tree Physiol. 21:541-547, doi: 10.1093/treephys/21.8.541.

Faust, M., A. Erez, L.J. Rowland, S.Y. Wang, and H.A. Norman. 1997. Bud dormancy in perennial fruit trees: Physiological basis for dormancy induction, maintenance, and release. $\mathrm{J}$. Amer. Soc. Hort. Sci. 32(4):623-629.

Freeman, M.W. and G.C. Martin. 1981. Peach floral bud break and abscisic acid content as affected by mist, light and temperature treatments during rest. J. Amer. Soc. Hort. Sci. 106:333-336.

Ganelevin, R. 2008. World-wide commercial applications of colored shade nets technology (ChromatiNet ${ }^{\circledR}$ ). Acta Hort. 770:199-203, doi: 10.17660/ActaHortic.2008.770.23.

Garner, W.W. and H.A. Allard. 1923. Further studies in photoperiodism, the response of the plant to relative length of day and night. J. Agr. Res. 23:871-920.

Gordon, D. and T.M. Dejong. 2007. Current-year and subsequent-year effects of crop-load manipulation and epicormic-shoot removal on distribution of long, short and epicormic shoot growth in Prunus persica. Ann. Bot. 99:323332, doi: $10.1093 / \mathrm{aob} / \mathrm{mcl} 262$.

Goto, N., T. Kumagai, and M. Koornneef. 1991. Flowering responses to light-breaks in photomorphogenic mutants of Arabidopsis thaliana, a long-day plant. Physiol. Plant. 83:209-215, doi: 10.1111/j.1399-3054.1991.tb02144.x.

Greer, D.H., J.N. Wünsche, C.L. Norling, and H.N. Wiggins. 2006. Root-zone temperatures affect phenology of bud break, flower cluster development, shoot extension growth and gas exchange of 'Braeburn' (Malus domestica) apple trees. Tree Physiol. 26:105-111, doi: 10.1093/ treephys/26.1.105

Guo, H., H. Yang, T.C. Mockler, and C. Lin. 1998. Regulation of flowering time by Arabidopsis photoreceptors. Science 279:1360-1363, doi: 10.1126/science.279.5355.1360.

Gur, A. 1985. Rosaceae-deciduous fruit trees, p. 355-389. In: A.H. Halevy (ed.). Handbook of flowering. Vol. 1. CRC Press, Boca Raton, FL.

Halliday, K.J., M. Koornneef, and G.C. Whitelam. 1994. Phytochrome B and at least one other phytochrome mediate the accelerated flowering response of Arabidopsis thaliana (L.) to low red/far red ratio. Plant Physiol. 104:1311-1315.

Hansen, P. 1971. 14C-studies on apple trees. VII. The early seasonal growth in leaves, flowers and shoots as dependent upon current photosynthates and existing reserves. Physiol. Plant. 25:469-473.
Hansen, P. and J. Grauslund. 1973. 14C-studies on apple trees. VIII. The seasonal variation and nature of reserves. Physiol. Plant. 28:24-32.

Hartmann, H. and S. Trumbore. 2016. Understanding the roles of nonstructural carbohydrates in forest trees - From what we can measure to what we want to know. New Phytol. 211:386403, doi: 10.1111/nph.13955.

Hauagge, R. and J.N. Cummins. 1991. Phenotypic variation of length of bud dormancy in apple cultivars and related Malus species. J. Amer. Soc. Hort. Sci. 116:100-106.

Hillmann, L., H. Kaufmann, and M. Blanke. 2016. Bioindicators for the dormancy status of fruit trees Bioindikatoren für den Dormanzstatus bei Obstgehölzen. Erwerbs-Obstbau 58(3):141-157.

Ito, A., H. Hayama, and Y. Kashimura. 2003. Sugar metabolism in spur bud during flower bud formation: A comparison between exposed and shaded buds of Japanese pear [Pyrus pyrifolia (Burm.) Nak.] 'Kosui'. J. Jpn. Soc. Hort. Sci. 72(4):253-261, doi: 10.2503/ jjshs. 72.253 .

Jackson, D.I. 1969. Effects of water, light and nutrition on flower-bud initiation in apricots. Aust. J. Biol. Sci. 22:69-75, doi: 10.1071/ BI9690069.

Jackson, I.E. and I.W. Palmer. 1977. Effects of shade on the growth and cropping of apple trees. II. Effects on components of yield. J. Amer. Soc. Hort. Sci. 52:253-266, doi: 10.1080/00221589.1977.11514754.

Kalcsits, L., S. Musacchi, D.R. Layne, T. Schmidt, G. Mupambi, S. Serra, M. Mendoza, and L. Asteggiano. 2017. Above and below-ground environmental changes associated with the use of photoselective protective netting to reduce sunburn in apple. Agr. For. Meteorol. 238:917, doi: 10.1016/j.agrformet.2017.01.016.

Kaufmann, H. and M. Blanke. 2017. Changes in carbohydrate levels and relative water content (RWC) to distinguish dormancy phases in sweet cherry. J. Plant Physiol. 218:1-5, doi: 10.1016/j.jplph.2017.07.004.

Kohlet, W., M.C. Candolfi-Vasconcelos, and M. Keller. 1996. Stress and stress recovering by grapevines. Bot. Helv. 106(1):73-84.

Lacointe, A., E. Deleens, T. Ameglio, B. SaintJoanis, C. Lelarge, M. Vandame, G.C. Song, and F.A. Daudet. 2004. Testing the branch autonomy theory: A $13 \mathrm{C} / 14 \mathrm{C}$ double-labelling experiment on differentially shaded branches. Plant Cell Environ. 27:1159-1168, doi: 10.1111/j.13653040.2004.01221.x.

Lang, G., J. Early, G. Martin, and R. Darnell. 1987. Endo-, para-, and ecodormancy: Physiological terminology and classification for dormancy research. J. Amer. Soc. Hort. Sci. 22:371-377.

Leyva, A., A. Quintana, M. Sanchez, E.N. Rodríguez, J. Cremata, and J.C. Sanchez. 2008. Rapid and sensitive anthrone-sulfuric acid assay in microplate format to quantify carbohydrate in biopharmaceutical products: Method development and validation. Biologicals 36:134-141, doi: 10.1016/ j.biologicals.2007.09.001.

Lin, C. 2000. Plant blue-light receptors. Trends Plant Sci. 5:337-342, doi: 10.1016/S13601385(00)01687-3.

Loescher, W.H., T. Mccamant, and J.D. Keller. 1990. Carbohydrate reserves, translocation, and storage in woody plant roots. J. Amer. Soc. Hort. Sci. 25:274-281.

Marafon, A.C., I. Citadin, L. do Amarante, F.G. Herter, and F.J. Hawerroth. 2011. Chilling privation during dormancy period and carbohydrate mobilization in Japanese pear trees. Sci. Agr. 68(4):462-468, doi: 10.1590/S010390162011000400011 . 
McQueen, J.C., P.E.H. Minchin, and W.B. Silvester. 2004. Changes in non-structural carbohydrate concentration in 1-year-old shoots of 'Braeburn' apple (Malus domestica) over two consecutive years. N. Z. J. Crop Hort. Sci. 32(3):319-323, doi: 10.1080/01140671.2004.9514310.

Meier, U., H. Graf, H. Hack, M. Hess, W. Kennel, R. Klose, D. Mappes, D. Seipp, R. Stauss, J. Streif, and T. Van Den Boom. 1994. Phänologische Entwicklungsstadien des Kernobstes (Malus domestica Borkh. und Pyrus communis L.) des Steinobstes (Prunus-Arten), der Johannisbeere (Ribes-Arten) und der Erdbeere (Fragaria $\times$ ananassa Duch.). Nachr. Dtsch. Pflanzenschutzd. 46(7):141153.

Pagter, M., U.B. Andersen, and L. Andersen. 2015. Winter warming delays dormancy release, advances budburst, alters carbohydrate metabolism and reduces yield in a temperate shrub. AoB Plants 7:Plv024, doi: 10.1093/ aobpla/plv024.

Painter, J.W. and G.E. Stembridge. 1972. Peach flowering response as related to time of gibberellins application. J. Amer. Soc. Hort. Sci. 7:389-390.

Park, J.Y., T. Canam, K.Y. Kang, F. Unda, and S.D. Mansfield. 2009. Sucrose phosphate synthase expression influences poplar phenology. Tree Physiol. 29:937-946, doi: 10.1093/treephys/tpp028.

Rageau, R., M. Bonhomme, J.P. Richard, and A. Erez. 1998. The climatic determinism of vegetative bud break on peach trees with no exposure to chilling: Some experimental results. Acta Hort. 465:511-520, doi: 10.17660/ActaHortic.1998.465.64.

Rajapakse, N.C. and Y. Shahak. 2007. Lightquality manipulation by horticulture industry, p. 290-312. In: G.C. Whitelam and K.J. Halliday (eds.). Annual Plant Reviews Volume 30: Light and Plant Development. Blackwell Publishing Professional, Ames, IA. doi: 10.1002/ 9780470988893.ch12.
Richardson, E., S. Seeley, and D. Walker. 1974. A model for estimating the completion of rest for 'Redhaven' and 'Elberta' peach trees. J. Amer. Soc. Hort. Sci. 9:331-332.

Ruiz, D., J. Egea, and P. Martínez-Gómez. 2005. Effect of shading and paclobutrazol during dormancy on apricot (Prunus armeniaca) productivity. N. Z. J. Crop Hort. Sci. 33(4):399406, doi: 10.1080/01140671.2005.9514376.

Samish, R.M., S. Lavee, and A. Erez. 1967. A concept of dormancy of woody plants with special reference to peach. Proceedings of the 17th International Horticultural Congress 3, $397-408$.

Shaltout, A.D. and C.R. Unrath. 1983. Rest completion prediction model for 'Starkrimson Delicious' apples. J. Amer. Soc. Hort. Sci. 108:957-961.

Signorelli, S., P. Agudelo-Romero, K. Meitha, C.H. Foyer, and M.J. Considine. 2018. Roles for light, energy, and oxygen in the fate of quiescent axillary buds. Plant Physiol. 176:1171-1181, doi: 10.1104/pp.17.01479.

Solomakhin, A. and M.M. Blanke. 2008. Coloured hailnets alter light transmission, spectra and phytochrome, as well as vegetative growth, leaf chlorophyll and photosynthesis and reduce flower induction of apple. Plant Growth Regulat. 56(3):211-218, doi: 10.1007/s10725-0089302-7.

Sperling, O., J.M. Earles, F. Secchi, J. Godfrey, and M.A. Zwieniecki. 2015. Frost induces respiration and accelerates carbon depletion in trees. PLoS One 10(12):E0144124, doi: 10.1371/ journal.pone.0144124.

Sperling, O., L.C.R. Silva, A. Tixier, G. ThérouxRancourt, and M.A. Zwieniecki. 2017. Temperature gradients assist carbohydrate allocation within trees. Sci. Rep. 7(1):3265, doi: 10.1038/s41598-017-03608-w.

Tixier, A., O. Sperling, J. Orozco, B. Lampinen, A Amico Roxas, S. Saa, J.M. Earles, and M.A. Zwieniecki. 2017a. Spring bud growth depends on sugar delivery by xylem and water recircu- lation by phloem Münch flow in Juglans regia. Planta 246:495-508, doi: 10.1007/s00425-0172707-7.

Tixier, A., A. Amico Roxas, J. Godfrey, S. Saa, D. Lightle, P. Maillard, B. Lampinen, and M.A. Zwieniecki. 2017b. Role of bark color on stem temperature and carbohydrate management during dormancy break in Persian walnut. J. Amer. Soc. Hort. Sci. 142(6):454-463, doi: 10.21273/JASHS04216-17.

Tixier, A., G.A. Gambetta, J. Godfrey, J. Orozco, and M.A. Zwieniecki. 2019. Non-structural carbohydrates in dormant woody perennials; the tale of winter survival and spring arrival. Front. Plant Sci. 2, doi: 10.3389/ffgc.2019. 00018.

Wang, S.Y. and M. Faust. 1988. Metabolic activities during dormancy and blooming of deciduous fruit trees. Isr. J. Bot. 37(2-4):227-243, doi: 10.1080/0021213X.1988.10677102.

Wareing, P.J. 1956. Photoperiodism in woody plants. Annu. Rev. Plant Physiol. 7:191-214.

Westwood, M.N. 1978. Temperate-zone pomology. Freeman, San Francisco, CA.

Yoshioka, H., K. Nagai, K. Aoba, and M. Fukumoto. 1988. Seasonal changes of carbohydrates metabolism in apple trees. Scientia Hort. 36:219-227, doi: 10.1016/0304-4238(88) 90056-8.

Yuan, H.Y., S. Saha, A. Vandenberg, and K.E. Bett. 2017. Flowering and growth responses of cultivated lentil and wild Lens germplasm toward the differences in red to far-red ratio and photosynthetically active radiation. Front. Plant Sci. 8:386, doi: 10.3389/fpls.2017.00386.

Zhuang, W., Z. Gao, L. Wen, X. Huo, B. Cai, and Z. Zhang. 2015. Metabolic changes upon flower bud break in Japanese apricot are enhanced by exogenous GA4. Hort. Res. 2:15046, doi: 10.1038/hortres.2015.46.

Zwieniecki, M.A., A. Tixier, and O. Sperling. 2015. Temperature assisted redistribution of carbohydrates in trees. Amer. J. Bot. 102:12161218, doi: 10.3732/ajb.1500218. 